commissioned in 1929 by the government of Southern Rhodesia (present-day Zimbabwe) to research the language varieties spoken by Zimbabwean natives. His work, which was premised on the quest for standardised, monolithic and homogeneous linguistic categories, marked the genesis of language politics in Zimbabwe. The Dokean legacy left an indelible mark on the terrain of language treatment and language policy formulation in postcolonial Zimbabwe. This paper uses Antonio Gramsci's hegemony theory to interrogate and problematise the contribution of Doke's pioneering work to language politics and language marginalisation in Zimbabwe. Gramsci's theory of hegemony posits that dominant social groups impose their supremacy over weaker groups either by overt coercion or by using more intellectual means of realising their dominance. The paper concludes by observing that the marginalisation of Ndebele in contemporary Zimbabwe cannot be fully understood outside the context of this Dokean legacy.

http://www.multilingual-matters.net

07-141 SunderLAND, JANE (Lancaster U, UK; j.sunderland@lancs.ac.uk), 'Parenting' or 'mothering'? The case of modern childcare magazines. Discourse \& Society (Sage) 17.4 (2006), 503-528.

doi:10.1177/0957926506063126

Many magazines devoted to the topic of the care of babies and young children now have titles which include some variation of parent rather than of mother (e.g. Parent and Child rather than Mother and Baby). This corresponds to evident new directions in social practices, and suggests a desire of the publishers to appeal to female and male readers. Whether both mothers and fathers are addressed and represented in the magazines makes these magazines particularly interesting sites for the study of fatherhood discourses. In this study, three magazines (Parents, Parenting and Baby Years) were analysed in terms of the extent to which the language of their advice features addressed women and/or men, and whether they could be seen as promoting 'shared parenting', 'hands-on' fatherhood, or at least a father-friendly environment. An examination of linguistic representation (in particular, of fathers), visuals, 'voices', gendered stereotypes and gendered discourses of parenting suggested that fathers are in fact not being fully addressed. These magazines may be lagging behind current social change and practices in 'Western' parenting.

http://das.sagepub.com

\section{Applied linguistics}

doi:10.1017/S0261444806284118

07-142 Bowles, Hugo (U Rome, Italy), Bridging the gap between conversation analysis and ESP - an applied study of the opening sequences of NS and NNS service telephone calls. English for Specific Purposes (Elsevier) 25.2 (2006), 332-357.

doi:10.1016/j.esp.2005.03.003

This article adopts conversation analysis (CA) techniques to examine the way in which participants in service telephone calls to bookshops negotiate their requests. The study, which is based on data from NS and NNS corpora, concentrates particularly on the reason-forcall sequence - the part of the telephone call opening in which the business of the phone call begins to be addressed by callers and receivers. A description is made of the pre-sequences which introduce reasonfor-call and the strategies deployed by NS and NSS in formulating their pre-sequences are analysed and compared. Two claims are made - firstly that conversation analysis data on telephone calls is an important and neglected source for LSP research and applications, and secondly that reason-for-call is a particularly difficult area for NNS and that the correct management of pre-sequences is crucial for successful negotiation of a request. Suggestions based on the analysis are given for LSP materials production for service calls. It is also suggested that this type of applied analysis could usefully be extended by LSP practitioners to other areas of institutional talk for which CA data is available.

http://www.elsevier.com

\section{7-143 Charles, Maggie (U Oxford Language} Centre, UK), Phraseological patterns in reporting clauses used in citation: A corpus-based study of theses in two disciplines. English for Specific Purposes (Elsevier) 25.2 (2006), 310-331. doi:10.1016/j.esp.2005.05.003

This study investigates the phraseological patterning that occurs in reporting clauses used to make references to others' research. It examines finite reporting clauses with that-clause complement and draws upon two corpora of theses written by native speakers in contrasting disciplines: approximately 190,000 words in politics/ international relations and 300,000 words in materials science. The findings show that both disciplines use significant numbers of these reporting clauses and that they most frequently occur as integral citations with a human subject. Following the work of [Francis, Hunston \& Manning (1996), Collins cobuild grammar patterns 1: Verbs. London: HarperCollins], the reporting verbs are analysed into semantic groups. Further evidence of patterning is found in both the verb groups and the tenses that occur. In both corpora, the most frequent verb group is argue (e.g. argue, note, suggest) and the most frequent tense is present (e.g. Skinner argues that. ..). In materials science, however, there are almost as many instances of the find/show verb group (e.g. show, find, observe) and these occur predominantly in past tense (e.g. Sun (1990) showed that. . .). The rhetorical functions of these patterns are discussed and explanations proposed based on genre and discipline. This research underlines the importance of phraseology in academic writing and 
ends by suggesting how working with patterns can be beneficial in raising students' language awareness.

http://www.elsevier.com

07-144 Csomay, Eniko (San Diego State U, USA), Academic talk in American university classrooms: crossing the boundaries of oral-literate discourse? Journal of English for Academic Purposes (Elsevier) 5.2 (2006), 117-135. doi:10.1016/j.jeap.2006.02.001

'Is academic speech "more like" casual conversation or academic writing?' [J. Swales, 'Metatalk in American academic talk: The cases of "point" and "thing". Journal of English Language, 29.1, 2001, p. 37]. Taking a corpusbased perspective to the analysis, this study compares the language of university classroom talk to academic prose and face-to-face conversation, positioning university classroom talk on the language continuum of speech and writing. More specifically, looking at a large number of linguistic features working together, I describe the language of 196 university class sessions (1.4 million words) collected at six universities across the United States. The analysis is based on Biber's multi-dimensional analytical framework [D. Biber, Variation across speech and writing. New York: Cambridge University Press, 1988].Overall, the results indicate that in these classrooms language features associated with both informational focus (as in academic prose) and involved discourse (as in face-to-face conversation) are equally present. Hence, this evidence-based research supports the argument that North American university classrooms exhibit language that can be treated as an interface on an oral-literate continuum.

http://www.elsevier.com

\section{7-145 Juola, Patrick, John Sofko \& Patrick \\ Brennan (Duquesne U, Pittsburgh, USA; juola@mathcs.duq.edu), A prototype for authorship attribution studies. Literary and Linguistic Computing (Oxford University Press) 21.2 (2006), 169-178. \\ doi:10.1093/llc/fql019}

Despite a century of research, statistical and computational methods for authorship attribution are neither reliable, well-regarded, widely used nor well-understood. This article presents a survey of the current state of the art as well as a framework for uniform and unified development of a tool to apply the state of the art, despite the wide variety of methods and techniques used. The usefulness of the framework is confirmed by the development of a tool using that framework that can be applied to authorship analysis by researchers without a computing specialization. Using this tool, it may be possible both to expand the pool of available researchers as well as to enhance the quality of the overall solutions, for example, by incorporating improved algorithms as discovered through empirical analysis.

http://llc.oxfordjournals.org

07-146 Kleiber, Georges (UFR Philosophie, linguistique et informatique, 67084 Strasbourg, France; Kleiber@umb.u-strasbg.fr) \& Francine GerhaRD-Krait, Quelque part: du spatial au non spatial en passant par l'indétermination et la partition [Quelque part: From the spatial to the non-spatial by way of indeterminacy and partition]. Journal of French Language Studies (Cambridge University Press) 16.2 (2006), 147-166.

doi:10.1017/S0959269506002407

Our aim is to describe the evolution of the adverbial phrase quelque part from its standard spatial use to its currently popular non-spatial uses, as yet unanalyzed, and exemplified by the following sequences: (a) Moi, ça m'embête quelque part de dire à un enfant euh non tu parles pas comme ça. Quelque part, il y a eu un abandon de la structure éducative 'It bothers me in some way to have to say to a child, er, don't speak like that. Somewhere, there has been a failure of the educational system' (comment made by an UMP deputy on the role of the parents and the school in the prevention of running away and truancy); (b) Je sais que Brian n'est pas mon enfant, mais quelque part il l'est aussi 'I know that Brian is not my child, but in some sense he is' (comment made by a woman whose 15-year-old daughter had a child whom she is helping to bring up, 27/01/03, TV broadcast); and (c) Quelque part, ça m'interpelle/m'attriste/me dérange/me chagrine 'In some sense, that appeals to me/saddens me/disturbs me/grieves me' (attested spoken examples). In the first part, we analyze the spatial meaning by giving particular emphasis to the two properties which characterize it, especially the feature of 'partition' which is generally neglected in the descriptions. Having distinguished non-spatial from spatial uses, we shall attempt in the second part: (i) to highlight two types of non-spatial uses; (ii) to explain these uses, with a view to grammaticalization, on the basis of the two semantic features postulated for spatial uses; and (iii) to describe the meaning effects to which they give rise and which partially explain their popularity.

http://journals.cambridge.org/jid_JFL

\section{7-147 NorthCott, JiLl \& GilLIAN Brown}

(Institute for Applied Language Studies, Edinburgh,

UK), Legal translator training: Partnership between teachers of English for legal purposes and legal specialists. English for Specific

Purposes (Elsevier) 25.2 (2006), 358-375.

doi:10.1016/j.esp.2005.08.003

Training legal English specialists is one area in which cooperation between discipline and language specialists is particularly valuable. Seven short excerpts from a short training course run jointly by teachers of English for legal purposes and legal specialists are presented 
and analysed to illustrate the contribution an ESP oriented approach, involving a high degree of subject specialist and ELP teacher cooperation can make to a very specific training need. These episodes provide illustrations of the interaction between legal translators and law lecturers centred on solving specific legal terminology questions. They are contextualized within an ethnographic account of courses designed and run for legislative translation teams from Central and Eastern European countries involved in European integration related translation activities. The data point to features of legal seminar discourse which would merit further investigation with possible applications for English for Academic Legal Purposes.

http://www.elsevier.com

\section{7-148 Palacios-Martínez, Ignacio \& ANa Martínez-Insua (U de Santiago de Compostela, Spain; iafeans@usc.es), Connecting linguistic description and language teaching: Native and learner use of existential there. International Journal of Applied Linguistics (Blackwell) 16.2 (2006), 213-231. \\ doi:10.1111/j.1473-4192.2006.00114.x}

This article emerges from the need to connect linguistic theory and language teaching to find concrete solutions to problems Spanish students confront when learning English. This study looks at existential there constructions taken from the following native and non-native written English corpora: the International Corpus of Learner English and the Santiago University Learner of English Corpus for the non-native set, and the Louvain Corpus of Native English Essays, Biber et al. (1999) and a subcorpus of the BNC for the native English group. This contrastive study reveals important differences in the use of there constructions as regards their frequency, structural complexity, polarity and pragmatic value. Important implications for the presentation and the pedagogical treatment of the there constructions can be derived from the results.

http://www.blackwellpublishing.com/journal.asp

\section{7-149 Pilz, Thomas, Wolfram Luther \&} Norbert Fuhr (U Duisburg-Essen, Germany; pilz@informatik.uni-duisburg.de), Rule-based search in text databases with nonstandard orthography. Literary and Linguistic Computing (Oxford University Press) 21.2 (2006), 179-186. doi:10.1093/Ilc/fql020

In this article, we describe our interdisciplinary project 'Rule-based search in text databases with nonstandard orthography (RSNSR)' in support of the conservation of cultural heritage, especially for the German reception of the philosopher Nietzsche. We present a rule-based fuzzy search engine that allows users to retrieve text data independently of its orthographical realization. The rules used are derived from statistical analyses, historical publications, linguistic principles, and expert knowledge. Our Web-based tool is intended for experts as well as interested amateurs. Along with its present features, further functions are currently worked out. Among them are automatic rule derivation and finer result classification through a generalized Levenshtein similarity measure. Our work is associated with the recently launched project Deutsch Diachron Digital (DDD) to build a complete diachronic corpus of German for the first time with texts from the ninth century (Old High German) to the present (Modern German).

http://llc.oxfordjournals.org

07-150 RichteR LoRENTZeN, LISE (U Trondheim, Norway; lise.lorentzen@hf.ntnu.no), Le

fonctionnement du pronom adverbial y et la concurrence entre y, là et là-bas en emploi spatial [The function of the adverbial pronoun $y$ and the competition between y, là and là-bas in spatial use]. Journal of French Language Studies (Cambridge University Press) 16.2 (2006), 167-185. doi:10.1017/S0959269506002419

In spite of their distinct nature and syntactic functions, the pronoun $y$ in its spatial use is in competition, semantically and pragmatically, with the two adverbs là and là-bas. In terms of cognitive accessibility, the referents of $y$ are shown to enjoy greater accessibility than those of the two adverbs. The three markers all have anaphoric uses. Although là and là-bas are also used deictically, such is not the case for $\gamma$. Là-bas is the only item able to mark distance with regard to the speaker. As far as thematic progression is concerned, the three markers can express the theme, but $y$ is never rhematic, in contrast to the other two. Lastly, $y$ and là-bas are more capable than là of marking a dynamic spatial process.

http://journals.cambridge.org/jid_JFL

07-151 Song, JAE Jung (U Otago, New Zealand; jaejung.song@stonebow.otago.ac.nz), The translatability-universals connection in linguistic typology: much ado about something Babel (John Benjamins) 51.4 (2005), 308-322.

Linguistic typologists tend to assume that there is a close connection between translatability and language universals (research) but this assumption has recently been called into question by Comrie, who claims that such a connection should be ignored in the practical enterprise of doing linguistics or will have a debilitating effect on the progress of linguistics as a discipline. This paper will demonstrate that translation is not only possible in principle but also has much relevance to language universals (research). First, to argue that translation is, in principle, not possible is to deny the basic relation between cognitive-conceptual content and language, mediated by translation. Moreover, the question of translatability is no longer looked upon as something either possible or impossible but translation is recognized as a process in which optimal solutions to translation are sought. 
Comrie's argument for the impossibility of translation is based on formal equivalence, a concept which is highly debatable, particularly within Translation Studies. Second, translation has much relevance to language universals (research), because universal constraints (for example, on relative clause formation) are formulated or defined in terms of grammatical context, which will only come to light through translation. This does not come as a surprise because the mediation between language and cognition is also done through translation. The role of translation in language universals (research) is much more than a mere heuristic. Translation is crucial to language universals.

http://www.benjamins.com

\section{7-152 Suárez, Octavio Santana, José Rafael Pérez Aguiar, luis losada García \& Francisco Javier Carreras Riudavets (U Las Palmas de Gran Canaria, Spain; fcarreras@dis.ulpgc.es), Functional disambiguation based on syntactic structures. Literary and Linguistic Computing (Oxford University Press) 21.2 (2006), 187-197. doi:10.1093/llc/fql016}

This article presents a disambiguation method which diminishes the functional combinations of the words of a sentence taking into account the context in which they appear. This process is built in two phases: the first phase is based on the local syntactic structures of the Spanish language and reaches an average yield of $87 \%$. The second one is supported by syntactic tree representation and pushes the results up to an approximate high end of $96 \%$. This process constitutes the starting point towards an automated syntactic analysis.

http://llc.oxfordjournals.org

07-153 Yakhontova, Tatyana (Ivan Franko National U L'viv, Ukraine), Cultural and disciplinary variation in academic discourse: The issue of influencing factors. Journal of English for Academic Purposes (Elsevier) 5.2 (2006), 153-167.

doi:10.1016/j.jeap.2006.03.002

This paper demonstrates the role of disciplinary context in shaping the common rhetorical and textual features of research texts in different languages and, more broadly, problematizes the validity of straightforward sociocultural explanations of rhetorical differences frequently used in the literature. The research is based on the contrastive genre analysis of English and Slavic (Ukrainian and Russian) conference abstracts in the field of applied mathematics. The features compared include rhetorical moves revealed and identified by reference to Swales' CARS model, their textual distribution, the paragraph organization of the texts, the syntactic structure of titles, and the use of personal pronouns I/we. The findings of the investigation compared with previously obtained results in the domain of applied linguistics show essential interdisciplinary variation between the two sets of data. This somewhat questions interpretations of rhetorical differences entirely based on the role of external determinants and highlights the importance of established traditions in various academic disciplines and cultures.

http://www.elsevier.com

\section{Pragmatics}

doi:10.1017/S0261444806294114

07-154 Bello, Richard (Sam Houston State U, USA; bello@shsu.edu), Causes and paralinguistic correlates of interpersonal equivocation. Journal of Pragmatics (Elsevier) 38.9 (2006), 1430-1441. doi:10.1016/j.pragma.2005.09.001

This paper examines the long standing theory of the Bavelas group which suggests that the only consistent cause of interpersonal equivocation is avoidanceavoidance conflict (AAC), and it also attempts to uncover a psycholinguistic profile of equivocation, especially in the form of paralinguistic cues such as dysfluencies. Participants responded orally to questions from hypothetical interlocutors within scenarios which manipulated both the presence/absence of AAC and level of situational formality. Their responses (72 messages) were audio taped, transcribed, rated for degree of equivocation, and coded for dysfluencies. Results of ANOVA showed that AAC not only resulted in more equivocation, but also that formality level interacted with AAC in influencing equivocation. Participants used filled pauses, surprisingly, in the condition within which they equivocated the least, although they produced other dysfluencies (combined) within conditions where they equivocated the most. Results are discussed in terms of the notion that filled pauses are special and in terms of interpersonal deception theory.

http://www.elsevier.com

07-155 Bosco, Francesca M. (Università e Politecnico di Torino, Italy; bosco@psych.unito.it), Monica Bucciarelli \& Bruno G. Bara, Recognition and repair of communicative failures: A developmental perspective. Journal of Pragmatics (Elsevier) 38.9 (2006), 1398-1429. doi:10.1016/j.pragma.2005.06.011

The aim of our study is to analyze the cognitive processes underlying recognition and repair of communicative failures. In particular, following the tenets of Cognitive Pragmatics, a theory of the mental processes underlying the comprehension and production of communicative acts, we propose an original taxonomy of the different kinds of failure which may occur in communicative interaction: Failure of the expression act, Failure of the actor's meaning, and Failure of the communicative effect. In particular, we operationally define both recognition and repair of the 